\title{
ICMAT 2009-IUMRS-ICA 2009 Conference Held in Singapore
}

The 5th International Conference on Materials for Advanced Technologies (ICMAT 2009), organized by the Materials Research Society of Singapore (MRS-S), was held jointly with the International Union of Materials Research Societies International Conference in Asia (IUMRSICA 2009) on June 28-July 3, 2009 in Singapore. With 23 symposia, nine plenary and three theme lectures in addition to the keynote, invited, and oral talks and poster presentations, the conference covered a broad range of topics in materials science, engineering, and technology. The joint conference also included the GEM ${ }^{4}$ / SMART Symposium on Infectious Diseases.

Speakers in Symposium R, on single crystals, focused specifically on crystal growth of FeAs-based superconductors. These materials, discovered only in 2007, are intensively studied and single crystals are already available. G. Behr (Leibnitz Inst., Dresden) reported use of the floating zone method for compounds with volatile elements including the new superconductors. The high pressure techniques, for the same group of superconductors, was applied by J. Karpinski (ETH, Zurich). Even from a flux, the superconductors were produced and reported by S. Snellius Pramana (Nanyang Tech. Univ., Singapore). A very different technique to induce superconductivity was presented by Y. Iwasa (Tohoku Univ., Japan). He and his group induced charge carriers by field effect and observed superconductivity in nominally insulated materials. The presentations in this Symposium demonstrated the need for new materials and that high-quality single crystals are critical for basic research and advanced industry.

Within Symposium G on plasmonics, H. Atwater (California Inst. of Technology) and N. Halas (Rice Univ.) delivered keynote lectures. Atwater highlighted his efforts at dispersion control, active materials integration, and metamaterials with an emphasis on applications to plasmonic modulators and enhanced efficiency of photovoltaic cells. Halas discussed how breaking symmetry of nanostructures can modify light-scattering signatures, how the quantum efficiency and radiative lifetime can be modified with proximal plasmonic structures, and how these can be exploited to enable new frontiers in bioimaging within tissue and single cells.

Those are just a few of the research highlights reported during the conference. Two industrial symposia were added to the

www.mrs.org.sg/icmat2009

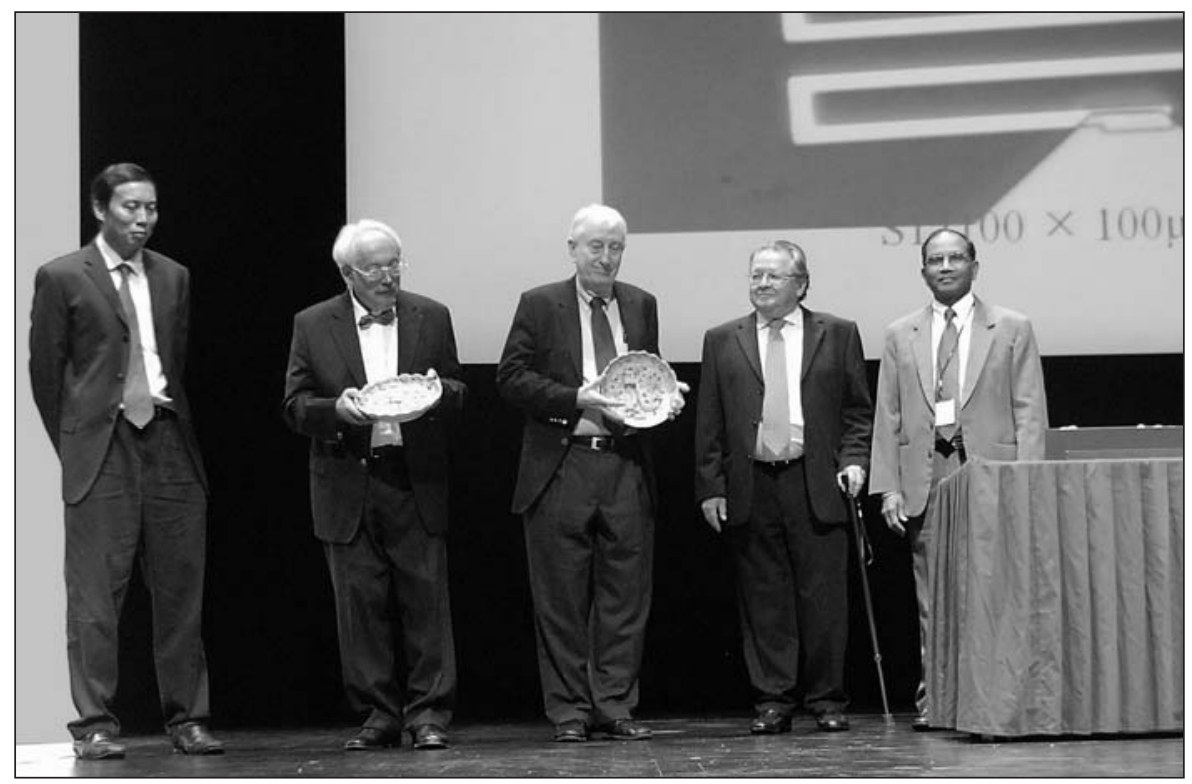

During the ICMAT 2009-IUMRS-ICA 2009 Conference in Singapore, mementos were given to the Nobel laureate speakers following their Public Lectures. (From left to right): Andrew Wee, Dean of Science, National University of Singapore; Nobel laureate Peter Doherty of the University of Melbourne; Nobel laureate Peter Gruenberg of Forschungszentrum Jülich; George Radda, Session Chair and Chair of the Biomedical Research Council, A*STAR Singapore; and B.V.R. Chowdari, Chair, ICMAT 2009 and President, MRS Singapore.

program this year, one on nanoimprint lithography and the other on microwave processing of materials. Another new initiative was a panel discussion on "Entrepreneurship in Materials Science and Engineering," with panelists Freddy Boey (Nanyang Tech. Univ., Singapore), Yet-Ming Chiang (Massachusetts Inst. of Technology, USA), Richard Friend (Cambridge Univ., UK), and Chad Mirkin (Northwestern Univ., USA). Lim Khiang Wee (Inst. of Materials Research and Engineering, Singapore) moderated.

The Conference was inaugurated by $\mathrm{Ng}$ Eng Hen, the Honorable Minister for Education, and Second Minister for Defence, Government of Singapore. The Ambassador of France, Pierre Buhler; the president of IUMRS, Howard Katz, and the deputy president of the National University of Singapore, Tan Eng Chye, also presented during the inaugural function.

Among the plenary speakers who also gave public talks were Nobel laureates Peter Gruenberg of the Institut for Festkorperforschung, Forschungszentrum Jülich, Hartmut Michel of Max Planck Institute of Biophysics, Frankfurt, and
Peter C. Doherty of the University of Melbourne.

The conference received over 2100 attendees from more than 40 countries and honored 37 Best Poster Awards. There was also an Exhibition with 43 Booths, showcasing products and services by manufacturers and book and journal publishers.

ICMAT 2009 was organized in association with the National University of Singapore, Nanyang Technological University, and the Institute of Materials Research and Engineering, with the support of A*STAR and many other national and international organizations. The conference received support from several organizations, including Singapore Tourism Board, Air Force Office of Scientific Research, Asian Office of Aerospace R\&D, Defence Science and Technology Agency, Korean Bone Bank, DSO National Laboratories, Institute of Physics Singapore, INMEET CMS Pte. Ltd., and TELTEC Semiconductor (Pacific) Pte. Ltd.

B.V.R. CHOWDARI President, MRS Singapore Chair, ICMAT2009 National University of Singapore 